\title{
Gendered perceptions of physical activity and diabetes in rural Bangladesh: a qualitative study to inform mHealth and community mobilization interventions
}

Joanna Morrison ${ }^{1}$, Hannah Jennings ${ }^{1}$, Kohenour Akter ${ }^{2}$, Abdul Kuddus², Jenevieve Mannell', Tasmin Nahar ${ }^{2}$, Sanjit Kumer Shaha², Naveed Ahmed ${ }^{2}$, Hassan Haghparast-Bidgoli', Anthony Costello ${ }^{1}$, AK Azad Khan ${ }^{2}$, Kishwar Azad², Edward Fottrell ${ }^{1}$

${ }^{1}$ University College London Institute for Global Health, London, United Kingdom, '2Diabetic Association of Bangladesh, Dhaka, Bangladesh

Correspondence to: Dr Joanna Morrison (Joanna.morrison@ucl.ac.uk)

\begin{abstract}
Background Diabetes prevalence is increasing rapidly in Bangladesh, and there is an urgent need to promote preventive behaviours for type 2 diabetes, such as maintaining a healthy body weight, eating healthily, avoiding tobacco and being active for 150 minutes per week.

Methods We used a qualitative methodology informed by the capability, opportunity, motivation theory of behaviour change to explore the factors affecting physical activity among men and women in rural Bangladesh. We conducted semi-structured interviews and focus group discussions with 64 purposively sampled participants with and without diabetes, and five health workers. From the results of descriptive content analysis, we identified key capabilities, opportunities and motivations to engage with in our mHealth and community mobilization interventions.
\end{abstract}

Results Men and women without diabetes lacked awareness about the need to remain physically active to prevent diabetes, and most felt that their activity levels were sufficient. Housework was not commonly perceived as physical activity among all respondents. These knowledge and capability gaps could be addressed through mHealth messaging and community mobilization providing information on sufficiency and types of physical activity to prevent and control diabetes. Men were physically active while working outside the home, whereas women felt unsafe and conspicuous, and were constrained by family commitments and social expectations of appropriate behaviour. Women engaged in strategies to protect their own and their family's reputations. These opportunity factors affecting physical activity indicated the need for strategies developed through participatory processes to challenge unhealthy gender norms and increase women's safety.

Conclusion Formative research data can enable the development of contextually relevant interventions. Data show that mHealth interventions should consider gendered barriers to physical activity, tailoring information to meet men's and women's needs, and that community mobilization interventions should enable unhealthy, gendered community norms to be challenged. Participatory interventions can enable communities to push the boundaries of socially acceptable behaviours to increase physical activity, helping to prevent and control diabetes.

Keywords: Bangladesh, behaviour change, exercise, gender, noncommunicable diseases, physical activity, type 2 diabetes

\section{Background}

An estimated 422 million people worldwide have diabetes, ${ }^{1}$ around $90 \%$ of whom have type 2 diabetes, which can be largely prevented by maintaining a healthy body weight, eating a healthy diet, avoiding tobacco and doing at least 150 minutes of moderate-intensity aerobic physical activity throughout the week. ${ }^{2}$ In adults aged 18-64 years, physical activity includes leisure time physical activity (e.g. walking, dancing, gardening, hiking, swimming), transportation (e.g. walking or cycling), occupational activity (i.e. work), household chores, play, games, sports or planned exercise, in the context of daily, family and community activities. ${ }^{2}$ An estimated $23 \%$ of the world's population are not meeting the minimum requirements for physical activity, and progress is particularly slow in lowand middle-income countries. ${ }^{3,4}$ Diabetes prevalence is 
Morrison et al.: Gender, physical activity and diabetes in rural Bangladesh

increasing rapidly in Bangladesh, with levels expected to reach $23.6 \%$ in men and $33.5 \%$ in women by $2030,{ }^{5}$ and there is an urgent need to develop and test population-level interventions. Our research explored the factors affecting physical activity in rural Bangladesh to inform the development of interventions to prevent and control diabetes. We consider how gender interacts with these factors and make recommendations for the development of behaviour-change interventions.

\section{Physical activity in Bangladesh}

The gender differential in physical activity in Bangladesh has been well documented. Men are generally more active than women, and urban women are least likely to be sufficiently active $^{6-8}$ Most physical activity occurs during work, or, for men, travelling to work..$^{9-11}$ Only a small proportion of men and women are physically active in their leisure time. ${ }^{9}$ Gender differences are most evident in young and old people. ${ }^{10,12}$ Studies largely concur with our recent epidemiological survey of adults aged 30 years and above in rural Bangladesh, ${ }^{13}$ which found that men and women aged 30-39 years engaged in adequate physical activity but that physical activity decreased sooner and to a greater extent among women as they got older. Less than $30 \%$ of women aged 70 years or more maintained adequate levels of physical activity, compared with approximately $60 \%$ of men in the same age group. Few studies have explored the reasons for physical inactivity among adult men and women in Bangladesh. ${ }^{14} \mathrm{~A}$ study of seven female and five male patients with diabetes attending a hospital in Dhaka found that time and place to exercise were barriers to physical activity. ${ }^{15}$

\section{Gender and behaviour change}

Gender is the socially constructed roles, behaviours, activities and attributes that a given society considers appropriate for men and women. ${ }^{16}$ Gender inequalities limit men's and women's health in multiple ways. Women's unequal access to services and resources and their increased likelihood of being poor and being exposed to violence negatively affect their health, while cultures of masculinity that encourage risk taking are harmful to men's health. ${ }^{17-19}$

Health promotion strategies have been accused of focusing on individual behaviour change instead of addressing gendered, structural barriers. ${ }^{20}$ Individual, skills-based and informational approaches to prevention and intervention are unlikely to be effective or sustained if they fail to create enabling community and familial contexts for men and women. ${ }^{21}$ In Bangladesh, interventions should acknowledge that it is a patriarchal society, with patrilocal marital practices whereby women come under the guardianship of their husband's family after marriage. ${ }^{22}$ Moreover, in Bangladesh, purdah (female seclusion) restricts women's freedom of movement and their access to public spaces. Women must behave appropriately, avoid attracting attention from men and uphold family honour. Norms about the division of labour within and outside the household, as well as norms about movement outside the household, are highly gendered. ${ }^{23}$

Our research partnership between the University College London Institute for Global Health and the Diabetic Association of Bangladesh conducted formative research to inform the development of two interventions that have been evaluated through a three arm cluster randomized controlled trial testing their effectiveness on noncommunicable disease risk factors, including lack of physical activity, overweight and obesity, and intermediate hyperglycaemia and diabetes. ${ }^{24}$ One intervention was a mobile health (mHealth) intervention informed by the capability, opportunity, motivation theory of behaviour change (COM-B), ${ }^{25,26}$ and the other was a group-based community mobilization intervention using participatory learning and action (PLA) cycles to promote healthy behaviours and transform communities. ${ }^{27,28}$ Both approaches (COM-B and PLA) acknowledge the socially constructed nature of behaviours, social constraints on behaviour and the need to address these to enable behaviour change. We found that there was a $20 \%$ reduction in diabetes and intermediate hyperglycaemia prevalence and a $10 \%$ reduction in the 2-year cumulative incidence of diabetes among those with intermediate hyperglycaemia in the PLA arm versus the control arm. There was no effect of mHealth on the combined prevalence of intermediate hyperglycaemia and diabetes, or the incidence of diabetes. ${ }^{29}$

This paper reports on the pre-trial formative research to inform the development of PLA and mHealth interventions. We used a qualitative methodology to explore community and individual perceptions of diabetes and associated risk factors (including physical activity) with men and women with and without diabetes, and health workers, in rural Faridpur, in order to design contextually appropriate content and methods for the mHealth and PLA interventions.

\section{Methods}

\section{Setting}

The pre-trial formative phase took around 10 months, from September 2015, and the interventions were implemented from June 2016 to December 2017. The trial was conducted in four upazilas (subdistricts) of Faridpur district in central Bangladesh. Faridpur is around $2000 \mathrm{~km}^{2}$ and has a population of over 1.7 million, with a mainly agricultural economy of jute and rice farming. Our baseline data show that the overall prevalence of intermediate hyperglycaemia and diabetes is $17.2 \%$ and $8.9 \%$ among men and $23.4 \%$ and $11.5 \%$ among women, respectively. ${ }^{30}$ The population can access low-cost health services from the Diabetic Association of Bangladesh hospital in Faridpur district headquarters, but in rural areas remoteness and flooding affect access to services, and the quality of health services is variable. The population is mainly Bengali and almost $90 \%$ are Muslim. ${ }^{31}$

\section{Sampling}

We purposively sampled 21 women and 13 men who had been diagnosed with type 2 diabetes, and 15 women and 15 men who had not been diagnosed with type 2 diabetes, in villages in Boalmari, Nagarkhanda and Saltha upazilas $(n=64)$. We did not collect data in Madhukhali, the fourth upazila included in the trial, as it was socioeconomically and sociodemographically similar to other trial upazilas, and we had reached data saturation. We purposively sampled participants over the age of 30 years, as risk of diabetes increases with age. To explore barriers to behaviour change in diverse groups, we purposively sampled participants from betteroff and poor households, estimated by observing participant house construction materials based on a classification used in previous studies. ${ }^{32}$ This method allows purposive sampling in 
Morrison et al.: Gender, physical activity and diabetes in rural Bangladesh

a less intrusive way than asking directly about socioeconomic status. ${ }^{33}$ We also purposively sampled five health workers from different upazilas who treated diabetes patients. The health workers were male, as there were very few female providers. Three were health workers who had received governmentaccredited diabetes training and worked in an upazila health complex, a family welfare centre and a local nongovernmental organization clinic. Two were male village doctors, also known as rural medical practitioners, who provided treatment and blood glucose testing through their private medicine shops. In Bangladesh, village doctors are unregistered and unregulated. Although some may have received some training on common illnesses such as diarrhoea, fever, cough and cold, ${ }^{34}$ the village doctors in this study had not received any training on diabetes treatment and referral.

\section{Data collection}

Participants with and without diabetes were approached in their homes, and health workers in their workplaces, by a trained, experienced Bangladeshi female qualitative researcher (KAk) and invited to participate. KAk conducted all the data collection in Bangla. The research team was not familiar with the villages and therefore KAk used snowball sampling to locate people with diabetes. The data collection is summarized in Table 1. Semi-structured interviews with six people with diabetes (three men and three women), and five people without diabetes (three women and two men), were conducted in or around their homes to explore their personal experiences of diabetes and risk factors. Care-seeking for diabetes and risk factors was explored in semi-structured interviews with five health workers. These interviews were conducted in their workplaces. Focus group discussions were conducted with five groups of people with diabetes (three groups of women and two groups of men) and four groups of people without diabetes (two groups of men and two groups of women) to explore community perceptions of diabetes and risk factors. Focus group discussions were conducted at a place of convenience for participants, in or around a participant's home. No one refused to participate.

Informed written or thumb-print consent was taken from all participants. Thumb-print consent is usual in this context, where there are high levels of illiteracy, and this procedure was approved by both ethics committees. The COM-B theory

Table 1. Data collection

\begin{tabular}{lccc}
\hline Respondents & Method & $\begin{array}{c}\text { Number of } \\
\text { interviews or } \\
\text { discussions }\end{array}$ & $\begin{array}{c}\text { Number of } \\
\text { participants }\end{array}$ \\
\hline Women without diabetes & SSI & 3 & 3 \\
\cline { 2 - 4 } Men without diabetes & FGD & 2 & 12 \\
\cline { 2 - 3 } Women with diabetes & SSI & 2 & 2 \\
\cline { 2 - 3 } & FGD & 2 & 13 \\
Men with diabetes & SSI & 3 & 3 \\
Health workers & SSI & 3 & 18 \\
Total & FGD & 2 & 3 \\
\hline
\end{tabular}

FGD: focus group discussion; SSI: semi-structured interview. of behaviour change was used in the development of topic guides, which explored the factors affecting participants' ability to carry out the WHO recommended behaviours to prevent and control diabetes. The topic guides were developed in English in discussion with KAk and the research team (the coauthors of this paper), translated into Bangla, and piloted by KAk in a suburb of Dhaka with two participants without diabetes (one woman and one man) and one health worker, and with one woman with diabetes at the Bangladesh Institute of Research and Rehabilitation in Diabetes, Endocrine and Metabolic Disorders hospital in Dhaka; these participants were not included in the subsequent study.

\section{Data management and analysis}

Data were digitally recorded and directly translated into English for analysis by trained and experienced translators, who were not part of the research team. Sections of transcripts were back-translated by KAk and checked against the recordings. $\mathrm{KAk}, \mathrm{HJ}$ and $\mathrm{JM}$ conducted preliminary analysis while data collection was ongoing. When themes were recurring, data collection ceased.

Three researchers (JM, $\mathrm{HJ}$ and $\mathrm{KAk}$ ) conducted descriptive content analysis. ${ }^{35} \mathrm{KAk}$ and $\mathrm{HJ}$ spoke English and Bangla, and all three were familiar with the south Asian context. We familiarized ourselves with the data, independently made lists of emergent themes and then discussed these together. We presented and discussed themes with the research team before finalizing the coding structure and coding transcripts in NVivo qualitative data analysis software (QSR International Pty Ltd, Version 11, 2015). Data were tabulated to compare barriers to and enablers of healthy behaviours within and among transcripts, and to compare data from participants of different genders and diabetes statuses. We then used the COM-B framework to analyse capability, opportunity and motivational domains that could be addressed in our interventions.

\section{Development of recommendations for mHealth and community mobilization interventions}

The mHealth intervention provided voice messages to mobile phone users who had voluntarily consented to receive the messages. We sought to make the messages contextually relevant and to ensure that they addressed barriers to healthy behaviours. The process of developing content for the mHealth intervention was informed by French et al. ${ }^{36}$ and is detailed elsewhere. ${ }^{26} \mathrm{HJ}$, JM and KAk participated in six steps to develop recommendations: (i) analysing the context of the intervention; (ii) detailing the intended outcomes and focus areas (based on the risk factors for diabetes - care-seeking, diet, physical activity, smoking and stress); (iii) listing enablers and barriers; (iv) categorizing these enablers and barriers according to COM-B; (v) suggesting relevant and feasible approaches for each barrier and ( $\mathrm{vi}$ ) producing a table of message content.

The PLA intervention used a paid group facilitator to stimulate discussion following a manual. Community members plan and implement locally prioritized actions on the basis of group and community discussions. ${ }^{37}$ We followed a similar process of recommendation development as for the mHealth intervention, but, instead of producing a table of message content, we developed example strategies to insert in the manual and use in training and supporting group facilitators. 
Morrison et al.: Gender, physical activity and diabetes in rural Bangladesh

\section{Ethical approval}

All procedures performed in this study were approved by the University College London Research Ethics Committee (4766/002) and the Ethical Review Committee of the Diabetic Association of Bangladesh (BADAS-ERC/EC/t5100246).

\section{Results}

We identified three main themes in our data relating to gendered definitions of physical activity, and to cultural and structural barriers restricting women's movement outside the home and restricting the type of physical activity that men and women felt they could undertake. Following the presentation of these themes, we describe how the interventions were informed by our findings.

\section{Gendered definitions of physical activity}

More participants with than without diabetes were aware that they should be physically active, to control their diabetes and their weight. Walking and working were the most common forms of physical activity for men with diabetes. Swimming was not considered to be physical activity by men or women and was perceived instead to refresh the body. Women considered praying and walking to be physical activity, and a routine of exercise signified discipline, moderation and religious commitment, which resulted in good health.

People who work diligently keep themselves healthy. If people ignore their work, they will become ill ... If someone is ill, then they need to work diligently and do their daily prayers, then they will be fine. (focus group discussion 021, women with diabetes)

Participants without diabetes felt sufficiently active in their everyday work or daily activities, and believed that only those with diabetes, high blood pressure or overweight needed to exercise. Women worked in their homes but did not necessarily define this as physical activity. One woman without diabetes said:

No, I don't do any kind of physical exercise ... I am usually busy doing housework like sweeping the floor or washing clothes. These are my activities. (semistructured interview 027, woman without diabetes)

Men without diabetes described walking or cycling to work, and walking during work, as well as the work itself as physical activity.

The work we do for our living is enough exercise. I think we do not need to do anything else for the sake of exercise. (focus group discussion 024, men without diabetes)

\section{"Moving carefully"}

All respondents discussed the social acceptability of women walking or doing other physical activity outside their homes. Women with diabetes discussed the need to protect their reputation and that of their family when going outside their homes.
She should move carefully ... in a village [a wife's movement] affects family honour and people criticize her and her family ... people will ask, "Where are you going so early?" (focus group discussion 029, women with diabetes)

A common perception was that women should not be outside the home unaccompanied and without purpose.

We don't usually go anywhere for an outing. I only go to places where I need to go. Like I have to take my daughter to the teacher's house for her tuition. (focus group discussion 012, women without diabetes)

Several men (including one male health worker) suggested that the places where men walked were unsuitable for women. Because women's work tended to be at home, it was more difficult to integrate physical activity into their daily activities, and they felt exposed when they went out walking.

Women with diabetes dealt with this conspicuousness by walking when they would not be seen.

I usually follow the doctor's suggestions about exercise in the early morning when there is no one in the road. I feel shy to do this in front of other people. (semi-structured interview 025, woman with diabetes)

Women with diabetes revealed that they dealt with the "fear of public disgrace" by not walking in the road. Others preferred to walk when men were not present.

If there are no men in the road, everyone likes walking, it's good to feel the breeze. (focus group discussion 011, women with diabetes)

Most women with diabetes preferred walking in groups; they felt safer and more motivated, and they enjoyed the exercise.

Yes, open space is good for us, but only if other people are there too. It does not feel good being there alone. (focus group discussion 021, women with diabetes)

Women reported that it was considered inappropriate for them to walk on muddy roads and that they were afraid of slipping.

Time poverty and gendered responsibilities

Women with diabetes felt "too busy" to exercise, particularly in the morning, when it was more socially acceptable to exercise. A male health worker said:

It is easier for men because they have less work to do in the morning than women. After the morning prayers men can go for 40-60-minute walk, but women are generally busy doing housework or making breakfast. Because they are busy, they can't walk or do any kind of physical exercise. (semi-structured interview 009, health worker)

When their housework and family responsibilities increased, women with diabetes stopped walking. Men found it easier to 
prioritize exercise, whereas women were expected to prioritize their families.

A man thinks about his body before anything, but women don't have time to do this. (semi-structured interview 010, health worker)

One woman gave an example of how it was difficult to exercise and look after the family:

One day I left rice to cook in the rice cooker and then I set out to walk ... but the electricity went off just after I left, so the rice wasn't cooked and I was late sending the rice to the field. My husband scolded me, and I haven't walked since then. (semi-structured interview 004, woman with diabetes)

Social acceptability prevented men and women from participating in sports. Many men used to play football, cricket or hadudu when they were younger but, as they aged, they perceived sport to be a futile and inappropriate use of time.

I have my own business now, so it's hard to find time for sports. The young guys have enough time for that. (focus group discussion 014, men without diabetes)

It wasn't socially acceptable for women to participate in sports, particularly in rural areas. One woman said:
I used to play badminton with my son or daughter or other kids when we were living in Dhaka. But the environment to play here doesn't exist. (focus group discussion 029, women with diabetes)

Table 2 describes how interventions could address capability, opportunity and motivational barriers to behaviour change relating to physical activity.

\section{Discussion}

Our study highlights the importance of having a gendered, contextual understanding of health-related behaviours. We discuss how interventions could address the key capabilities, opportunities and motivations to promote physical activity.

\section{Capability}

Capability refers to the knowledge (psychological capability) or skills (physical capability) required to do the recommended behaviour. Our study, and others, ${ }^{38,39}$ found that participants without diabetes lacked knowledge that physical activity could prevent diabetes, and believed that only people with diabetes needed to do "extra" physical activity. mHealth messages could increase knowledge about the need to exercise for diabetes prevention, and increase understanding among people with and without diabetes about what is sufficient exercise to prevent diabetes. PLA interventions could discuss this information through open questions such as "How do

Table 2. Barriers to healthy behaviours and implications for interventions

\begin{tabular}{|c|c|c|}
\hline Barriers to healthy behaviours & $\begin{array}{l}\text { Suggestions for what group-based } \\
\text { interventions could do }\end{array}$ & $\begin{array}{l}\text { Suggestions for what mHealth messages } \\
\text { could provide }\end{array}$ \\
\hline $\begin{array}{l}\text { Capability } \\
\text { - Perceptions of leisure time physical activity } \\
\text { as just for people with diabetes and } \\
\text { disciplined men } \\
\text { - Existing levels of physical activity among } \\
\text { people without diabetes are perceived } \\
\text { sufficient to stay healthy }\end{array}$ & $\begin{array}{l}\text { Engage communities } \\
\text { - Raise awareness among men and women } \\
\text { of the need to be physically active, through } \\
\text { public events and family discussions } \\
\text { - Provide information on risk factors and } \\
\text { prevention } \\
\text { - Integrate specific information regarding } \\
\text { sufficiency of physical activity for health }\end{array}$ & $\begin{array}{l}\text { Information about risk factors, prevention, } \\
\text { and sufficiency of physical activity in daily } \\
\text { tasks }\end{array}$ \\
\hline $\begin{array}{l}\text { Opportunity } \\
\text { - Lack of appropriate places to walk for } \\
\text { women } \\
\text { Women are perceived as not prioritizing } \\
\text { their family and are suspected of dishonour } \\
\text { if physically active } \\
\text { - Women do not feel safe to walk } \\
\text { unaccompanied and in the same space as } \\
\text { men } \\
\text { - Sports perceived as only for younger men } \\
\text { with free time } \\
\text { Walking perceived as the pursuit of } \\
\text { disciplined men } \\
\text { Women work at home and therefore have } \\
\text { limited opportunities for physical activity } \\
\text { while travelling to work }\end{array}$ & $\begin{array}{l}\text { Engage community leaders } \\
\text { - To improve facilities and safety for women } \\
\text { - To challenge harmful gender norms } \\
\text { - To lead on behaviour change, including } \\
\text { walking at different times of the day } \\
\text { to emphasize variation in routine as } \\
\text { acceptable } \\
\text { Engage men, women and families } \\
\text { - Encourage men and women to challenge } \\
\text { gender norms, providing particular support } \\
\text { to women to be physically active } \\
\text { - Encourage walking in groups } \\
\text { - Encourage families to ensure time is } \\
\text { managed for women to be physically active } \\
\text { - Conduct participatory mapping of places to } \\
\text { walk } \\
\text { - Raise awareness among men and women } \\
\text { of the need to be physically active, through } \\
\text { public events and family discussions }\end{array}$ & $\begin{array}{l}\text { - Information and examples of home-based } \\
\text { physical activity } \\
\text { - Information and examples of how women } \\
\text { and men can challenge gender norms } \\
\text { - Encouragement to women to seek support } \\
\text { from family and friends when engaging in } \\
\text { physical activity } \\
\text { - Examples of "normal" men and women who } \\
\text { have busy and/or erratic lifestyles but are } \\
\text { able to integrate physical activity into their } \\
\text { lives } \\
\text { - Examples of role models in the form of men } \\
\text { and women doing physical activity while } \\
\text { travelling to work }\end{array}$ \\
\hline $\begin{array}{l}\text { Motivation } \\
\text { - Perceived lack of control over diabetes and } \\
\text { health }\end{array}$ & $\begin{array}{l}\text { Engage communities } \\
\text { - Raise awareness about prevention and } \\
\text { control of diabetes } \\
\text { - Encourage active ageing for men and } \\
\text { women through families }\end{array}$ & $\begin{array}{l}\text { - Information about strategies to prevent and } \\
\text { control diabetes } \\
\text { Examples of role models in the form of } \\
\text { active men and women who are in older } \\
\text { age brackets }\end{array}$ \\
\hline
\end{tabular}


you know when you have done enough exercise?" and discuss how information about the need for physical activity, and sufficiency of physical activity, can be disseminated and further understood. This could include discussion with non-group members or implementing public physical activity events. Farming, physical labour and housework are all forms of physical activity, ${ }^{2}$ but the last was not often recognized as such. Messaging could equip women and men with the skills to estimate the sufficiency of their physical activity to prevent or control diabetes in relation to the exercise that they normally do, while going beyond reinforcement of gendered constructs of women as caregivers doing household work and men as doing work outside the home. ${ }^{40}$

\section{Opportunity}

Opportunity refers to social influences, environmental context and resources that constrain or enable recommended behaviours. Key elements of this domain were socially endorsed behaviours, time poverty and the gendered division of labour, and safety and social change.

\section{Socially endorsed behaviours}

Some women identified features of the external environment, such as muddy roads and uneven paths, as preventing them from being physically active. They feared falling over and the resultant embarrassment. PLA interventions could invite groups and communities to map and assess community spaces for physical activity, considering their suitability and sufficiency, and take action to improve these spaces if necessary. PLA interventions could also encourage communities to address local norms about appropriate behaviour, through dialogue or through engaging with community leaders. The need to behave appropriately curtailed physical activity in both men and women. Dominant perceptions of walking as being practised by disciplined men only, and sports as an activity for young men, restricted physical activity. mHealth messages could provide examples of older, "normal" men and women, illustrating how they cope with or seek to change established social rules.

\section{Time poverty}

Advice about physical activity should acknowledge the different time constraints and daily routines of men and women, and the gendered division of labour. ${ }^{41-43}$ Men were more likely to do manual work outside the home than women, and it would be easier for men than women to increase their physical activity within their daily routines. We found that health workers often advised walking as a form of physical activity, without acknowledging that this was particularly difficult for women or those with a high workload. Giving advice that cannot be followed may induce guilt or stress, ${ }^{18,44}$ and interventions should emphasize the important role of family and community social support in behaviour change..$^{45}$ PLA interventions could engage with health workers to encourage them to be mindful of gender issues when giving advice. PLA interventions could also ensure that members of the wider family are made aware of their role in enabling physical activity for all family members, whether by accompanying female family members to enable them to exercise outside the home or by allocating time for physical activity within the household. mHealth messages could provide examples of feasible and acceptable physical activity for both men and women.

\section{Safety and social change}

Purdah affected women's physical activity. Women were concerned about their own safety and engaged in strategies to protect their family's reputation and protect themselves. They walked in groups, they walked at times when others couldn't see them or when men were not around, and they walked in private places or in open spaces depending on which they perceived to be safer. A national survey on genderbased violence in 2015 found that $73 \%$ of married women had experienced violence from their husband in their lifetime and $55 \%$ had experienced violence in the past year. Twenty-eight per cent of women had experienced non-partner violence. ${ }^{46}$ PLA and mHealth messaging could encourage women to walk in groups and invite communities to develop strategies to reduce gender-based violence to increase physical activity.

Men and women may make strategic choices not to challenge community and household norms to control or prevent diabetes. ${ }^{47}$ They may seek to avoid retribution or be influenced by adaptive preferences $^{48}$ that legitimize women's restricted opportunities, and shape how men and women engage in and evaluate social change. ${ }^{49}$ While transformation of harmful norms is necessary, incremental change in gender norms through engaging with men, families, communities and local power structures may be a safer option for many women and families. PLA approaches can enable women and men to push the boundaries of what is socially acceptable to the extent that they are comfortable and challenge social norms as a group..$^{50}$

\section{Motivation}

Motivation refers to the brain processes that energize and direct behaviour. ${ }^{51}$ Many participants with diabetes felt incapable of controlling their diabetes and unable to maintain a routine of exercise. Increased awareness about the possibilities for integrating exercise into everyday activities would help develop confidence and capability. Women's caring and household management role and men's role as economic provider were important to their identities, ${ }^{52,53}$ and we found that they prioritized these roles. Interventions should recognize the effect of diabetes and ageing on self-esteem, and support men and women to feel more in control of their health as they age. This could be facilitated by using positive role models in mHealth messages, and by implementing locally defined community and family actions to encourage older adults to be physically active.

\section{Limitations}

Gender is embodied in institutions, policies and systems, and we did not engage adequately with these in our study. All the researchers leading the study design, developing the topic guides, collecting data, and carrying out the preliminary analysis and interpretation of the data were women. We addressed the potential bias resulting from this by presenting and discussing the research with the mixed-gender trial research team, after piloting and during the initial and latter stages of data analysis. The gender of the researcher may have affected the willingness of men to disclose information.

\section{Conclusion}

To inform the development of interventions to promote physical activity and to prevent and control diabetes, it is important to consider the contextual influences on physical activity and 
Morrison et al.: Gender, physical activity and diabetes in rural Bangladesh

how they are experienced by different genders. Our research has highlighted key capabilities, opportunities and motivations that could be addressed through interventions. Communitybased groups working through PLA cycles and mHealth messaging may improve knowledge and motivation to change behaviour, as well as enabling engagement with community or opportunity barriers to behaviour change. Messaging and groups have been designed to stimulate discussion about locally appropriate action to challenge unhealthy, gendered norms, and to promote contextually relevant physical activity. Interventions seeking to encourage community-wide efforts to increase women's safety, work towards gender equality and challenge negative concepts of masculinity will have multiple benefits, not least in increasing men's and women's ability to be physically active to prevent and control diabetes.

Acknowledgements: The study team would like to thank all the participants involved in this study and the Bangladesh D-Magic Trial Steering Committee (Professor Graham Hitman, Professor Martin McKee, Dr Dina Balabanova, Dr David Beran, Dr Katherine Fielding, Dr Lou Atkins and Ms Sophia Wilkinson) for their input into the overall design of the project.

Source of support: This work was supported by the UK Medical Research Council (grant number MR/M016501/1) under the Global Alliance for Chronic Diseases Diabetes Programme.

\section{Conflict of interest: None declared.}

Authorship: JM, HJ, and KAk conceived of and designed the study and analysed the data. JM wrote the first draft of the manuscript. AK, TN, SKS, NA, HH-B, KA, JMa and EF participated in data interpretation. $A C$ and $A K$ provided managerial support to the study. All authors read and commented on drafts of the manuscript.

How to cite this paper: Morrison J, Jennings H, Akter K, Kuddus A, Mannell J, Nahar T, Shaha SK, Ahmed N, Haghparast-Bidgoli H, Costello A, Azad Khan AK, Azad K, Fottrell E. Gendered perceptions of physical activity and diabetes in rural Bangladesh: a qualitative study to inform mHealth and community mobilization interventions. WHO South-East Asia J Public Health. 2019;8(2):104-111. doi:10.4103/2224-3151.264855.

\section{References}

1. Global report on diabetes. Geneva: World Health Organization; 2016 (https://apps.who.int/iris/bitstream/handle/10665/204871/9789241565 257_eng.pdf;jsessionid=B3C1361787CBF2DAC9F608F3E3C5EC6F? sequence $=1$, accessed 24 July 2019).

2. Global recommendations on physical activity for health. Geneva: World Health Organization; 2010 (https://apps.who.int/iris/bitstream/handle/ 10665/44399/9789241599979_eng.pdf;jsessionid=73FE5804686A89 B0C02332B94503424B?sequence=1, accessed 24 July 2019).

3. Global status report on noncommunicable diseases 2014. Geneva: World Health Organization; 2014 (https://apps.who.int/iris/bitstream/ handle/10665/148114/9789241564854_eng.pdf?sequence=1, accessed 24 July 2019).

4. Sallis J, Bull F, Guthold R, Heath G, Inoue S, Kelly P et al. Progress in physical activity over the Olympic quadrennium. Lancet. 2016; 388(10051):1325-36. doi:10.1016/S0140-6736(16)30581-5.

5. Rahman MM, Akter S, Jung J, Rahman MS, Sultana P. Trend, projection, and appropriate body mass index cut-off point for diabetes and hypertension in Bangladesh. Diabetes Res Clin Pract. 2017;126:43-53. doi:10.1016/j.diabres.2017.01.008.

6. Uddin R, Burton N, Khan A. Perceived environmental barriers to physical activity in young adults in Dhaka City, Bangladesh does gender matter? Int Health. 2018;10(1):40-6. doi:10.1093/inthealth/ihx057.

7. Rawal LB, Biswas T, Khandker NN, Saha SR, Bidat Chowdhury MM, Khan AN et al. Non-communicable disease (NCD) risk factors and diabetes among adults living in slum areas of Dhaka, Bangladesh. PLoS One. 2017;12(10):e0184967. doi:10.1371/journal.pone.0184967.

8. Saquib J, Saquib N, Stefanick M, Khanam M, Anand S, Rahman M et al. Sex differences in obesity, dietary habits, and physical activity among urban middle-class Bangladeshis. Int J Health Sci (Qassim). 2016;10(3):365-72. doi:10.12816/0048730.

9. Ranasinghe $C$, Ranasinghe $P$, Jayawardena R, Misra A. Physical activity patterns among South-Asian adults: a systematic review. Int $J$ Behav Nutr Phys Act. 2013;10(116). doi:10.1186/1479-5868-10-116.

10. McKay A, Laverty A, Shridhar K, Alam D, Dias A, Williams J, et al. Associations between active travel and adiposity in rural India and Bangladesh: a cross-sectional study. BMC Public Health. 2015;15(1087). doi:10.1186/s12889-015-2411-0.

11. Moniruzzan M, Ahmed M, Zaman M. Physical activity levels and associated socio-demographic factors in Bangladeshi adults: a crosssectional study. BMC Public Health. 2017;17(59). doi:10.1186/s12889-016-4003-z.

12. Khan A, Burton N, Trost S. Patterns and correlates of physical activity in adolescents in Dhaka city, Bangladesh. Public Health. 2017;145:75-82. doi:10.1016/j.puhe.2016.12.011.

13. Fottrell E, Ahmed N, Shaha SK, Jennings H, Kuddus A, Morrison J et al. Diabetes knowledge and care practices among adults in rural Bangladesh: a cross-sectional survey. BMJ Glob Health. 2018;3(4):e000891. doi:10.1136/bmjgh-2018-000891.

14. Sohal T, Sohal P, King-Shier K, Khan N. Barriers and facilitators for type-2 diabetes management in South Asians: a systematic review. PLoS One. 2015;10(9):e0136202. doi:10.1371/journal.pone.0136202.

15. Islam S, Biswas T, Bhuiyan F, Mustafa K, Islam A. Patients' perspective of disease and medication adherence for type 2 diabetes in an urban area in Bangladesh: a qualitative study. BMC Res Notes. 2017;10(1):131. doi:10.1186/s13104-017-2454-7.

16. The gender guide for health communication programs. Washington (DC): Center for Communication Programs; 2003 (https://www.who. int/management/genderguide.pdf, accessed 24 July 2019).

17. Hawkes S, Buse S. Gender and global health: evidence, policy and inconvenient truths. Lancet. 2013;381(9879):1783-7. doi:10.1016/S0140-6736(13)60253-6.

18. Doyal L. Sex, gender and health: the need for a new approach. BMJ. 2001;2001(323):1061-3. doi:10.1136/bmj.323.7320.1061.

19. Courtenay W. Constructions of masculinity and their influence on men's well-being: a theory of gender and health. Soc Sci Med. 2000;50(10):1385-401. doi:10.1016/S0277-9536(99)00390-1.

20. Östlin P, Eckermann E, Mishra U, Nkowane M, Wallstam E. Gender and health promotion: a multisectoral policy approach. Health Promot Int. 2006;21(Suppl. 1):25-35. doi:10.1093/heapro/dal048.

21. Kostick K, Schensul S, Singh R, Pelto P, Saggurti N. A methodology for building culture and gender norms into intervention: an example from Mumbai, India. Soc Sci Med. 2011;72(10):1630-8. doi:10.1016/j.socscimed.2011.03.029.

22. Kabeer N. Between affiliation and autonomy: navigating pathways of women's empowerment and gender justice in rural Bangladesh. Dev Change. 2011;42(2):499-528. doi:10.1111/j.1467-7660.2011.01703.x

23. Hossain M, Bose M. Nature and impact of women's participation in economic activities in rural Bangladesh: insights from household surveys. Dhaka: Centre for Policy Dialogue; 2004 (https://ideas.repec. org/p/pdb/opaper/41.html, accessed 24 July 2019).

24. Fottrell E, Jennings $\mathrm{H}$, Kuddus $\mathrm{A}$, Ahmed N, Morrison J, Akter K et al. The effect of community groups and mobile phone messages on the prevention and control of diabetes in rural Bangladesh: study protocol for a three-arm cluster randomised controlled trial. Trials. 2016;17(1):600. doi:10.1186/s13063-016-1738-x.

25. Michie S, van Stralen M, West R. The behaviour change wheel: a new method for characterising and designing behaviour change interventions. Implement Sci. 2011;6(42). doi:10.1186/1748-5908-6-42.

26. Jennings $\mathrm{H}$, Morrison J, Akter K, Kuddus A, Ahmed N, Shaha S et al. Developing a theory-driven contextually relevant $\mathrm{mHealth}$ 
intervention. Glob Health Action. 2019;12(1):1550736. doi:10.1080/16549716.2018.1550736.

27. Marston C, Hinton R, Kean S, Baral S, Ahuja A, Costello A et al. Community participation for transformative action on women's, children's, and adolescents' health. Bull World Health Organ. 2016;94(5):376-82. doi:10.2471/BLT.15.168492.

28. Prost A, Colbourn T, Seward N, Azad K, Coomarasamy A, Copas A et al. Women's groups practising participatory learning and action to improve maternal and newborn health in low-resource settings: a systematic review and meta-analysis. Lancet. 2013;381(9879):1736-46. doi:10.1016/S0140-6736(13)60685-6.

29. Fottrell E, Ahmed N, Morrison J, Kuddus A, Shaha S, King C et al. Community groups or mobile phone messaging to prevent and control type 2 diabetes and intermediate hyperglycaemia in Bangladesh (DMagic): a cluster randomised controlled trial. Lancet Diabetes Endocrinol. 2019;7(3):200-12. doi:10.1016/S2213-8587(19)30001-4.

30. Fottrell E, Ahmed N, Shaha S, Jennings H, Kuddus A, Morrison J et al. Distribution of diabetes, hypertension and non-communicable disease risk factors among adults in rural Bangladesh: a crosssectional survey. BMJ Glob Health. 2018;3(6):e000787. doi:10.1136/bmjgh-2018-000787.

31. Population and housing census 2011. Dhaka: Bangladesh Bureau of Statistics, Government of the People's Republic of Bangladesh; 2013 (http://203.112.218.66/WebTestApplication/userfiles/Image/BBS/ Socio_Economic.pdf, accessed 22 July 2019).

32. Bangladesh Demographic and Health Survey 2014. Dhaka and Rockville: National Institute of Population Research and Training (NIPORT), Mitra and Associates and ICF International; 2016 (https:// dhsprogram.com/pubs/pdf/FR311/FR311.pdf, accessed 28 July 2019).

33. Morrison J, Osrin D, Alcock G, Azad K, Bamjan J, Budhathoki B et al. Exploring the equity impact of a maternal and newborn health intervention: a qualitative study of participatory women's groups in rural South Asia and Africa. Int J Equity Health. 2019;18(1):55. doi:10.1186/s12939-019-0957-7.

34. Ahmed SM, Hossain MA, Chowdhury MR. Informal sector providers in Bangladesh: how equipped are they to provide rational health care? Health Policy Plan. 2009;24(6):467-78. doi:10.1093/heapol/czp037.

35. Green J, Thorogood N. Qualitative methods for health research. London: SAGE Publications; 2004.

36. French SD, Green SE, O'Connor DA, McKenzie JE, Francis JJ, Michie $S$ et al. Developing theory-informed behaviour change
interventions to implement evidence into practice: a systematic approach using the theoretical domains framework. Implement Sci. 2012;7(1):38. doi:10.1186/1748-5908-7-38.

37. Morrison J, Akter K, Jennings HM, Kuddus A, Nahar T, King C et al. Implementation and fidelity of a participatory learning and action cycle intervention to prevent and control type 2 diabetes in rural Bangladesh. Global Health Res Policy. 2019;4(19). doi:10.1186/s41256-019-0110-6.

38. Fatema K, Hossain S, Natasha K, Chowdhury H, Akter J, Khan T et al. Knowledge attitude and practice regarding diabetes mellitus among nondiabetic and diabetic study participants in Bangladesh. BMC Public Health. 2017;17(1):364. doi:10.1186/s12889-017-4285-9.

39. Islam F, Chakrabarti R, Dirani M, Islam T, Ormsby G, Wahab M et al. Knowledge, attitudes and practice of diabetes in rural Bangladesh: the Bangladesh Population based Diabetes and Eye Study (BPDES). PLoS One. 2014;9(10):e110368. doi:10.1371/journal.pone.0110368.

40. Daykin N, Naidoo J. Feminist critiques of health promotion. In: Bunton R, Nettleton S, Burrows R, editors. The sociology of health promotion: critical analysis of consumption, lifestyle and risk. London: Taylor and Francis; 2005.

41. Brown W, Mielke G, Kolbe-Alexander T. Gender equality in sport for improved public health. Lancet. 2016;388(10051):1257-8. doi:10.1016/S0140-6736(16)30881-9.

42. Sun F, Norman I, While A. Physical activity in older people: a systematic review. BMC Public Health. 2013;13(449). doi:10.1186/1471-2458-13-449.

43. Jain M. Addressing complexities of measuring women's time use in Bangladesh. Washington (DC): Agriculture for Nutrition and Health; 2015 (http://a4nh.cgiar.org/2015/02/02/addressing-complexitiesof-measuring-womens-time-use-in-bangladesh/, accessed 24 July 2019).

44. Saleh F, Mumu S, Ara F, Hafez M, Ali L. Non-adherence to selfcare practices \& medication and health related quality of life among patients with type 2 diabetes: a cross-sectional study. BMC Public Health. 2014;14(431). doi:10.1186/1471-2458-14-431.

45. Shawon M, Hossain F, Adhikary G, Das Gupta R, Hashan M, Rabbi M et al. Attitude towards diabetes and social and family support among type 2 diabetes patients attending a tertiary-care hospital in Bangladesh: a cross-sectional study. BMC Res Notes. 2016;9(286). doi:10.1186/s13104-016-2081-8.

46. Report on violence against women (VAW) survey 2015. Dhaka Bangladesh Bureau of Statistics, Government of the People's Republic of Bangladesh; 2016 (http://evaw-global-database. unwomen.org/-/media/files/un\%20women/vaw/vaw\%20survey/ bangladesh $\% 20$ vaw $\% 20$ survey $\% 202015$.pdf?vs=2125, accessed 24 July 2019).

47. Bajaj S, Jawad F, Islam N, Mahtab H, Bhattarai J, Shrestha D et al. South Asian women with diabetes: psychosocial challenges and management: consensus statement. Indian J Endocrinol Metab. 2013;17(4):548-62. doi:10.4103/2230-8210.113720.

48 Sen A. Gender inequality and theories of justice. In: Nussbaum M, Glover J, editors. Women, culture and development. Oxford: Clarendon Press; 1995.

49. Kabeer N. Economic pathways to women's empowerment and active citizenship: what does the evidence from Bangladesh tell us? J Dev Stud. 2017;53(5):649-63. doi:10.1080/00220388.2016.1205730.

50. Seferiadis A, Cummings S, Maas, Bunders J, Zweekhorst M. From "having the will" to "knowing the way": incremental transformation for poverty alleviation among rural women in Bangladesh. Action Res. 2017;15(1):57-76. doi:10.1177/1476750316685876.

51. Cane J, O'Connor D, Michie S. Validation of the theoretical domains framework for use in behaviour change and implementation research. Implement Sci. 2012;7(37). doi:10.1186/1748-5908-7-37.

52. Hasan M, Aggleton P, Persson A. The makings of a man: social generational masculinities in Bangladesh. J Gend Stud. 2018;27(3):347-61. doi:10.1080/09589236.2017.1388773.

53. Salway S, Jesmin S, Rahman S. Women's employment in urban Bangladesh: a challenge to gender identity. Dev Change. 2005;36(2):317-49. doi:10.1111/j.0012-155X.2005.00413.x. 